\title{
Generation Post-COVID-19: The Time for Anti-Economics Has Come: Health, Minimalism and Rest
}

\author{
Julia M. Puaschunder ${ }^{1,2}$ \\ ${ }^{1}$ The New School, Department of Economics, School of Public Engagement, New York, NY 10003, USA, \\ Julia.Puaschunder@newschool.edu,www.juliampuaschunder.com \\ ${ }^{2}$ Columbia University, Graduate School of Arts and Sciences, Julia.Puaschunder@columbia.edu, \\ http://blogs.cuit.columbia.edu/jmp2265
}

\begin{abstract}
This paper makes the heterodox economic case of missing attention to health, minimization and rest in business, finance and economics. The COVID-19 pandemic has been addressed as a once-in-a-lifetime opportunity to a Great Reset. Started at the end of 2019, COVID-19 has been spreading around the world for over a year by now and no clear end is foreseeable yet. While vaccination and medication opportunities to cure the disease have improved impressively and steadily, the COVID-19 healthcare crisis also entails around 10 to over $30 \%$ of previously COVID-infected to be suffering from long haul symptoms. While our first understanding of post-COVID infection long haul symptoms, impetus and cure is still missing, there is hardening evidence that the newly emerging Generation COVID-19 Long Haulers may comprise of 0.3-1.659 billion previously infected with recurrent symptoms of fatigue, headaches and breathing problems as well as a set of debilitating memory fog and emotional distress. With this generation of COVID-19 Long Haulers, who are by around 70$75 \%$ female and of a median age in their $30 \mathrm{~s}$ and $40 \mathrm{~s}$, a dramatic shift to demand for health, minimalism and rest is predicted to emerge. Neoclassical ideas of business, finance and economic research have a limited understanding of health. Maximization pledges of productivity driven industries in business, finance and economics do not account for minimalism. Foremost behavioral economics started to address cognitive overload and decision-making failures in a too complex world. There is no appreciation for rest in finance and economics. All these trends of attention to health, minimalism and rest the COVID-19 Long Haulers generation may change lastingly.
\end{abstract}

KEYWORDS: Behavioral economics, Business, Coronavirus, COVID-19, Crisis, Debilitation, Economics, Emotional impairment, Fatigue, Finance, Headaches, Heterodox Economics, Generation COVID-19 Long Haulers, Healthcare, Medication, Memory fog, Minimalism, Preventive care, Respiratory symptoms, Rest, Self-measurement, Vaccination

\section{Introduction}

The novel Coronavirus COVID-19 started at the end of 2019, when it was first diagnosed in China. To this day, there are over 150 million reported infections with COVID-19 and over 3 million deaths reported around the world (Worldometer 2021). A new angle of the healthcare crisis became apparent early on in cases reporting continuous impairment after an infection. Most recently, an information wave broke on growing numbers of previously infected, who report either constant impairment or recurrent waves of symptoms after their infection - even after having been tested negative for COVID-19.

This so-called Long COVID affects $10-30 \%$ of people who have symptomatic infection with Sars-CoV-2 as a symptomatic disease lasting longer than 12 weeks (Harrison 2021). The range of Long COVID symptoms is wide and diffuse but early on a social media Facebook Long Hauler group consisting of 1567 long-term strugglers after a COVID infection identified almost 100 long-haul effects that include fatigue (100\%), muscle or body aches $(66.8 \%)$, shortness of breath or difficulty breathing $(65.1 \%)$, difficulty concentrating or focusing $(59 \%)$, inability to exercises or be active $(58.5 \%)$, headache $(57.6 \%)$, difficulty sleeping $(49.9 \%)$, 
anxiety (47.6\%), memory problems (45.6\%) and dizziness $(41.9 \%)$ among the top long haul symptoms (Britt 2020). Follow up studies revealed a cluster of symptoms ranging from chest pain and cough; dyspnea and cough; anxiety and tachycardia; abdominal pain and nausea; and low back pain or joint pain (Antrim 2021). The list of symptoms is still updating and includes by now cognitive dysfunction, numbness or tingling, loss of taste, smell and other senses such as hearing and vision, muscle pain, tinnitus, heart rate and blood pressure issues, gastrointestinal complaints, insomnia, depression and anxiety but also dermatological anomalies (Ault 2021; Doheny 2021). Most recently, studies emerge that report multi-organ functioning debilitation after COVID-19 (Harrison 2021). To all these clusters of symptoms is common to create a longterm debilitation and a patient innate need for recovery, health and rest.

With research estimating about 10 up to more than $30 \%$ of COVID-19 patients become Long Haulers, the newly emerging Generation COVID-19 Long Haulers has the potential to change our world lastingly. This article speculatively discusses the impact of a wave of COVID19 Long Haulers emerging in society. The demographics of Long Haulers to consist of fairly young individuals in their 30 s and 40 s suggests that this usually most productive part of society will break a wave of lasting corporate, finance and economic changes. With this estimated 0.31.659 billion strong cohort of COVID-19 Long Haulers living for an estimated 40-50 years longer, the way we conduct business, finance and economic growth may change dramatically. Their longing for health will drive the overall demand for healthcare and preventive medical care. The cognitive debilitation will increase an already detected deficiency gap to make decisions in a complex world to even further appreciation for unwinding and breaking down a complex world in minimalism. Economic theory will have to be expanded for attention to rest, which has been seen as problematic and unfavorable in the standard neoclassical business conduct and economic cycle theories. Future research may thus address a more heterodox economics angle giving space and attention for re-writing corporate, finance and economic models with appreciation for health, minimalism and rest.

\section{Demographics}

COVID-19 is a worldwide pandemic, which started 2019 in China. COVID-19 is caused by a coronavirus called SARS-CoV-2 that causes in older adults and those with severe underlying medical conditions, like heart or lung disease or diabetes, serious complications and illness.

As of the end of April 2021, there are over 150 million reported infections with COVID19 and over 3 million deaths reported around the world (Worldometer, 2021). Actual infection rates may be higher, ranging from 5\% to 20\% (ScienceDaily, 2021).

Of the COVID-infected, there are three different major scenarios described based on the immune system response: (1) Symptomatic COVID-19 trajectory with variable severity leading to disease and likely hospitalization due to respiratory symptoms, cytokine storms and multiorgan function impairment; (2) Mild symptomatic COVID-19 trajectory leading to signs and symptoms of evasion of immune surveillance as well as (3) Asymptomatic COVID-19 spreaders, who may or may not turn symptomatic (Baig 2020).

Who falls into what group of immune responses to COVID-19 is yet unclear but certain trajectory propensities seem to depend on gender, age, pre-existing conditions and viral load received at exposure to the virus alongside a range of genetic predispositions and environmental pre-COVID episodes (Baig 2020). For instance, of the currently roughly 20 million COVID-19 infected, $99.4 \%$ appear to have only mild conditions and only $0.6 \%$ is considered as serious and/or critically ill (Worldometer 2021). Of the closed cases so far, in $2 \%$ the disease led to death, $98 \%$ are considered to have recovered (Worldometer 2021).

A recent study of 6500 COVID Long Haulers estimates that $10-30 \%$ of all infected have the potential to become Long Haulers, who experience lasting effects of a previous COVID infection. The average COVID Long Hauler appears to be in their late 30s and early 40s with 
female making up an estimated $70-75 \%$ of all Long Haulers (Rubin 2020). As COVID-19 is a fairly novel disease and long-term effects are detected and monitored over a period of at least 8 weeks to 6 months, our understanding of long COVID syndrome is still developing in its infancy.

What preliminary data appears to suggest so far is that COVID Long Haulers appear to be infected that never fully recover back to their pre-COVID-19 levels even weeks or months after having experienced first symptoms. Some Long Haulers continuously experience debilitating symptoms that either are prevalent constantly or come back in waves or relapse with ongoing, old and/or new symptoms. This so-called post-COVID-19 syndrome or postacute sequelae of SARS-CoV-2 infection (PASC) currently appears to be similar to other postviral infections such as Lyme disease, for instance, that can cause similar long-lasting mild symptoms after a viral infection.

Long COVID affects $10-30 \%$ of people who have symptomatic infection with Sars$\mathrm{CoV}-2$ and is defined as symptomatic disease lasting longer than 12 weeks (Harrison, 2021). While a solid nomenclature of COVID-19 Long Haulers is yet to be determined, it appears that three long-hauling clusters may emerge of which, the symptomatic COVID-19 infected with heightened cases of COVID and likely severe symptoms such as cytokine storms and hospitalization, complications and multi-organ diseases will likely have more organ impairment that leads to long-term labile conditions (Baig 2020). The symptomatic COVID-19 infections with mild symptoms may fall into two categories of either persistent viral load in the body that creates waves of mild signs and symptoms of a disease with persistent abnormal serological findings similar to Lyme disease or post-Ebola infection (Baig 2020). The third cluster of COVID-19 Long Haulers will be those with immune cell deficiencies after an evasion of immune surveillance and potential inflammation similar to rheumatoid arthritis (Baig 2020).

In finding a cure for these three clusters of Long Haulers, potentially the type of Long Haulers will determine the remedy. While in cluster 1 of organ damage the type of damage and type of organ will set the range of possibilities for convalescence, in cluster 2 so far anti-COVID vaccinations have shown promising results (Goodman 2021) and in cluster 3 potentially the overall status and balance of the immune system will become the focus of attention for finding back to a state of balance. In all three groups and in the path forward with a chronic and longterm COVID Long Hauling generation, healthcare will pay more attention to whole-rounded medical care with focus on prevention, self-monitoring and long-term balance.

\section{Estimations}

As of April 2021, COVID-19 has infected over 150 million people around the world. Already in October 2021, the World Health Organization estimated that around 10 percent of the world population have been infected by COVID-19 (NBCNews, The Associated Press, October 5, 2020). Cumulative cases are estimated to be 5-20 times greater than confirmed ones (Noh \& Danuser 2021). Substantial undocumented infections, the speed and unpredictable cluster outbreaks but also asymptomatic infections that turn into Long Haulers with conditions popping up long after the initial infection obscure the true size of the potential debilitation caused by the novel Coronavirus (Noh \& Danuser 2021). Estimations are expecting in total of up to 40-70\% of the world's population to get infected with COVID-19 (Coleman 2020). If considering worst case that $70 \%$ of the world's population to get infected with COVID-19 and 10 -over $30 \%$ end up as Long Haulers, the world could end with 0.3-1.659 billion Long Haulers. If considering additional fall-outs of COVID vaccination failures and breakthrough infections, the number may even be higher. What will the world change to if considering the vast amount of Long Haulers forming a Generation COVID-19 Long Haulers? 


\section{Generation COVID Long Haulers}

The $21^{\text {st }}$ century may be coined as an unprecedented time of anti-economics that values everything contrary to the neoclassic idea of economics of productivity, maximization and efficiency. With this generation of COVID-19 Long Haulers, who are by around $70-75 \%$ female and of a median age in their $30 \mathrm{~s}$ and $40 \mathrm{~s}$, a dramatic shift to demand for health, minimalism and rest is predicted to emerge.

Neoclassical ideas of business, finance and economic research have a limited understanding of health and wellbeing. Traditional economic growth theories considered capital and labor as essential growth factors for every economy (Puaschunder 2020). Exogenous growth theory is centered on exogenous shocks - like new technology innovations or natural crises, such as pandemics - as major drivers or downturns of economic growth measured in capital and labor impact. Endogenous growth theory then drew attention to dynamic variable interactions between capital and labor but also endogenous growth derived from ideas, innovation and learning. Growth concepts were opened up for innovation generated in productive group interaction and learning inside firms in teams, learning-by-doing while performing tasks and learning-by-using of new technology. The outbreak of the novel Coronavirus (COVID-19) heightened attention for hygiene and healthcare. According to exogenous growth theory, the health risk exposure to the exogenous shock of COVID-19 differs between employees, firms, industries, environments and countries. Health of labor capital but also a risk-free working culture, environment, industry and country will flourish growth in a COVID-19-struck economy. In endogenous growth theory terms, team hygiene and group monitoring of the collective health status but also learning-to-preventing holds future economic growth potential. Applications of COVID-19 adjusted growth models should also include inequality of growth in the digital age (Puaschunder 2020).

Regarding healthcare changes, a cadre of chronically debilitated and sick will lead to a drive to alleviate chronic diseases. Already as early as the end of 2020, the United States Congress already approved 1.15 billion USD in funding over four years for the National Institute of Health to support research into the prolonged health consequences of SARS-CoV2 infections (National Institute of Health 2021). Of the investigated symptoms, chronic fatigue, headaches, shortness of breath and memory fog range among the top mentions that will draw attention to find cures for. Immune system related research and attention to the immune response based on activation levels but also inflammatory disfunctioning will likely gain on research attention, when considering the long-term effects of COVID Long Haulers report.

Since the onset of the COVID-19 pandemic, there has been a moving trend from large metropolitan areas noticed to more rural areas. People have moved to the suburbs or rural areas and reconnected with environmental conditions during a crucial time in light of climate change. Today, there is a heightened demand for climate stabilization featuring concerted mitigation and adaptation efforts. Different environmental efforts could shape the global environmental governance required in the $21^{\text {st }}$ century, ranging from formal institutions (major global conferences and treaties), legal regimes, informal arrangements, intergovernmental relationships, nongovernmental organizations, global capital markets and multinational corporations (Puaschunder, forthcoming). Attempts to curb human-made carbon emissions that are offsetting the climate change dilemma may be in contrast to economic growth. For instance, fiscal policies and carbon tax but also monetary and credit policies attentive to environmental degradation may curb productivity. Creative ecowellness options and sustainable lifestyle innovations may emerge that pay tribute to health and well-being within the given natural constraints of ecological limits. Future cities may also see ecologic pricing reforms that pay tribute to the trend into environmentalism. Active cityscape projects may feature forestation to absorb $\mathrm{CO}_{2}$ from the atmosphere but also behavioral changes. Already now we find a trend towards individualized cars and further behavioral changes will likely force transportation to 
become more hygienic and individualized. Lastly, the cities of tomorrow will likely feature intergenerational conscientiousness in protecting elder and low immune system risk groups from contagious diseases (Puaschunder 2020b). Corporate settings, industry demands and economic growth will likely stem from attuning to this trend of ecowellness and sustainable lifestyles in the future.

In the personal sphere, there is currently a deurbanization trend going on or what Brunnermeier calls the Doughnut effect that the urban population enjoys time off from large metropolitan areas and moves to the suburbs or even country side. Current home owner booms in remote areas like Arizona, Texas or Florida speak for people's preference to escape cities. Corporations are still offering to opt for home offices and many of the corporate headquarters have moved to less crowded, more affordable locations. Cities are still seen as disadvantaged to control large crowds and ventilation in skyscrapers. The ongoing ecowellness trends has not only changed our perception of closeness and contact with others, it has also revolutionized interior design in offices with glass and plastic protection. Outdoors city and landscape has been shaped by deurbanization as well. New community development in harmony with nature are forming in so-called agri- or agrohoods, neighbourhoods that are directly attuned to the surrounding and celebrate the natural and cultural heritage. In interior design for the private living space, cleanliness has become key. Attention to healthy nutrition is on the rise for Long Haulers, who appear to have a craving for minimalistic stimulation at home that often also features a Biophilia design, which resembles nature and sustainable fabrics.

Another trend of the post-COVID world that will likely stay around will be the selfmonitoring and self-measurement of body functions with artificial intelligence and self-testing kits having arisen dramatically in record speed in light of the COVID pandemic. With the fear of patients to visit doctors and attend a hospital for care during the pandemic, new online consultation revolutions have started that are likely to be continued after COVID and be exacerbated by Long Haulers who will likely face fast-paced symptom changes and a novel set of easily-changing health status conditions.

On a more global macro-economic level, the Green New Deal and European Green Deal as post-COVID-19 recovery paths forward include sustainability pledges. A sustainable finance taxonomy may also innovatively include healthcare reforms and governmental funding of longterm health pledges in order to address a wave of COVID-19 Long Haulers. Attention to the integration of AI in healthcare and medicine should be coupled with insights of a cadre of partially debilitated that may even have instability in symptomatic wave of disabilities. AI could be integrated to support when patients face difficulty that may onset unpredictably and/or periodically. Human-AI compatibility will be key and big data insights used in order to find patterns in waves of multi-organ functionality deficiencies.

As for economic changes, COVID Long Haulers appear to have a preference for unwinding speed and mental overloads. While standard neoclassical economic theory is based on the believe that efficiency maximization based on productivity gains and activation level increases is the ultimate preference of all individuals, COVID Long Haulers may develop - for the first time in economic history - a large-scale demand for attention to disability, rest and relaxation and thereby drive a trend of the economics of slowness. Legal professionals will address attention to the growing cohort of disabled and debilitated workforce. Drawing from behavioral insights, the laws of human productivity after rest but also different time discounting over life calculating time use strategically will be required in the future to better and more accurately describe workforce trends (Puaschunder, 2021, forthcoming).

With this generation of COVID-19 Long Haulers a dramatic shift to demand for health, minimalism and rest is predicted to emerge. Maximization pledges of productivity driven industries in business, finance and economics do not account for minimalism. Foremost behavioral economics started to address cognitive overload and decision making failures in a too complex world (Puaschunder, forthcoming). There is no appreciation for rest in finance 
and economics. All these trends of attention to health, minimalism and rest the COVID-19 Long Haulers generation may change lastingly.

With Long Haulers facing trends of changing health conditions, novel workforce uncertainty will become a topic of discussion for corporate governance and business contingency planning. The newly-imposed obligation of corporations to look after a healthy work environment will likely remain beyond COVID and pass on some rights to corporations to monitor and track the health status of the workforce (Gelter \& Puaschunder, forthcoming). Corporations will have to become attuned to the health situation of employees and will likely divide capital into artificial intelligence and more unpredictable human workforce with appreciation for rest and relaxation. New activation studies will be needed guided by behavioral specialists that find the right balance between work and rest. These studies will likely be inspired by activation research such as the Yerkes-Dodson law that predicted an individual activation level of the overall immune system status determining individual potentials and overstimulation leading to potential work deficiencies and quality of life impairments (Yerkes \& Dodson 1908).

All these trends of economics of unwinding, relaxation and rest will likely become major drivers of a new revolution in economics that focuses away from profit maximization, productivity and speed to minimalism, relaxation and rest. Previously avoidable states of rest, inaction and unproductivity that were recently deemed as problematic will leverage as a luxury and esteemed maximization. The maximization of minimalism is likely to become a trend that will change the way society produces, consumes and gratifies. Here again, AI and robotics may keep an economic growth level while human beings start focusing on relaxation and letting go.

\section{References}

Antrim, Aislinn. 2021. "Study: Many Long-Haul COVID-19 Patients Were Asymptomatic During Initial Infection." Pharmacy Times, March 12, 2021. Retrieved at https://www.pharmacytimes.com/view/studymany-long-haul-covid-19-patients-were-asymptomatic-during-initial-infection.

Ault, Alicia. 2021. “Are there COVID-19-related 'long-haul' skin issues?” Dermatology News, January 28, 2021. Retrieved at https://www.mdedge.com/dermatology/article/235153/coronavirus-updates/are-there-covid-19related-long-haul-skin-issues.

Baig, Abdul Mannan. 2020. "Chronic COVID syndrome: Need for an appropriate medical terminology for longCOVID and COVID long-haulers." Journal of Medical Virology 93(5): 2555-2556.

Britt, Robert Roy. 2020. Long-lasting COVID Symptoms: Early research helps quantify coronavirus long-hauler' experiences. Elemental, August 14, 2020. Retrieved at https://elemental.medium.com/new-survey-identifies98-long-lasting-covid-symptoms-87935b258a3e.

Coleman, Justine. 2020. "Virus expert: As much as 70 percent of world's population could get coronavirus." The Hill, March 2, 2020. Retrieved at https://thehill.com/policy/healthcare/public-global-health/485602-virusexpert-as-much-as-70-percent-of-worlds.

Doheny, Kathleen. 2021. "Neurological Symptoms frequent in COVID Long-Haulers." Webmd Health News, March 23, 2021. Retrieved at https:/www.webmd.com/lung/news/20210323/neurologic-symptomsfrequent-covid-long-haul-partients.

Gelter, Martin \& Julia Margarete Puaschunder. Forthcoming. "COVID-19 and comparative corporate governance." Journal of Corporation Law.

Goodman, Brenda. 2021. "Some with long-haul COVID see relief after vaccination." Webmd Health News, March 17, 2021. Retrieved at https:/www.webmd.com/vaccines/covid-19-vaccine/news/20210317/some-withlong-haul-covid-see-relief-after-vaccination.

Harrison, Arielle. 2021. "70\% of COVID long haulers have impaired organs up to 4 months after infection, study finds." KUTV, April 27, 2021. Retrieved at https://kutv.com/news/local/70-of-long-haulers-have-impairedorgans-up-to-4-months-after-covid-19-infection.

National Institutes of Health (NIH). 2021. NIH launches new initiative to study "Long COVID." February 23, 2021. Retrieved at https://www.nih.gov/about-nih/who-we-are/nih-director/statements/nih-launches-newinitiative-study-long-covid.

NBCNews, The Associated Press. 2020. Covid-19 may have infected 10 percent of world's population, WHO says. October 5, 2020. Retrieved at https://www.nbcnews.com/news/world/covid-19-may-have-infected-10percent-world-s-population-n1242118. 
Noh, Jungsik \& Gaudenz Danuser. 2021. "Estimation of the fraction of COVID-19 infected people in the U.S. states and countries worldwide." PLoS ONE 16(2): 2021: e0246772.

Puaschunder, Julia Margarete. 2020a. "Economic Growth in Times of Pandemics." Proceedings of the ConScienS Conference on Science \& Society: Pandemics and their Impact on Society, pp. 1-9, September 28-29, 2020.

Puaschunder, Julia Margarete. 2020b. "The Future of the City after COVID-19: Digitionalization, Preventism and Environmentalism." Proceedings of the ConScienS Conference on Science \& Society: Pandemics and their Impact on Society, pp. 125-129, September 28-29, 2020.

Puaschunder, Julia Margarete. 2021. Behavioral Economics and Finance: Nudging and Winking to make Better Choices. Springer Nature.

Puaschunder, Julia Margarete. Forthcoming. Verhaltensökonomie und Verhaltensfinanzökonomie: Ein Vergleich europäischer und nordamerikanischer Modelle. Springer Gabler.

Rubin, Rita. 2020. “As their numbers grow, COVID-19 'Long Haulers' stump experts." Journal of the American Medical Association 324 (14): 1381-1383.

ScienceDaily. 2021. "Severe undercounting of COVID-19 cases in U.S., other countries estimated via model." February 8, 2021. Retrieved at https:/www.sciencedaily.com/releases/2021/02/210208142434.htm.

Worldometer COVID live update, April 28, 2021. Retrieved at https://www.worldometers.info/coronavirus/.

Yerkes, Robert M. \& John Dillingham Dodson. 1908. "The relation of strength of stimulus to rapidity of habitformation." Journal of Comparative Neurology and Psychology 18(5): 459-482. 